\title{
Business as usual?
}

\author{
The inspirational political leadership needed to tackle dangerous climate change may be lacking, but \\ some business leaders are taking the initiative.
}

As delegates unpack their bags after their long-haul flights to sunny Durban for the 17th Conference of the Parties (COP17) to the United Nations Framework Convention on Climate Change negotiations (28 November-9 December), life goes on. Attendees will no doubt be mindful - and if not, they should be - that the seemingly relentless increase in global greenhouse-gas emissions and the consequent rise in mean global temperature continue apace. This is despite the Kyoto Protocol, the agreements reached in Cancún last year and the Copenhagen Accord of 2009. Even the global economic downturn has by all accounts failed to put the brakes on emission rates.

If deniers of climate change thought that 'Climategate' would once and for all have put paid to all this nonsense, the conclusions of the Berkeley Earth Surface Temperature Project (http://berkeleyearth.org/), which have received considerable publicity in the past month, suggest otherwise. Based on a comprehensive review of available evidence 15 large datasets with records going back as far as 1800 - the project scientists claim to have incontrovertible evidence that the Earth is warming, thus confirming previous peer-reviewed and published studies. A major reported conclusion of the study is that global land mean temperature has risen by nearly $1^{\circ} \mathrm{C}$ since the mid-1950s — with negligible room for doubt.

In a frank and candid interview on page 437, the director of the Berkeley project, physicist Richard Muller, explains the rationale behind the new re-analysis, and indeed why, in his view and that of others, it was necessary at all given the weight and credibility of existing evidence. He highlights, in particular, the need to assuage the legitimate concerns of sceptics, and indeed many interested onlookers, regarding what has been perceived previously as lack of transparency in some quarters of the climate change community an issue publicly acknowledged by a number of prominent climate researchers over recent months. As an aside, Muller draws a clear and considered distinction between open-minded sceptics, whom he respects, and outright deniers who are unlikely to be budged from their preconceived views, whatever the facts.

The project also tackled other potential confounding factors that have come under scrutiny, including the possible biasing effects of using data from weather stations near large, heat-generating cities, and those of data adjustment, selection and exclusion. The conclusion seems to be that, although potential biases exist, their significance is minimal and the Earth is indeed warming up as feared. The findings of the study are the subject of four scientific papers submitted for peer review, and the dataset on which the conclusions are based is publicly available, as are the analysis programs, which is to be applauded.

Professing a degree of healthy scientific scepticism himself, Muller suggests that much of this apparent temperature rise perhaps a much larger proportion than that assumed in the Intergovernmental Panel on Climate Change reports so far - could be a manifestation of natural variability. Nevertheless he is unwilling - presumably based on what is known from both empirical and modelling approaches - to exclude the possibility that up to half of the observed warming is down to human activities such as fossil-fuel burning and land-use change. His only plea is that sceptics, and perhaps less optimistically erstwhile deniers, should consider the accumulating evidence for global warming with a similar level of objectivity and open-mindedness. And who in all seriousness can argue with that?

So, if we accept that global warming is real and at least in substantial measure anthropogenic, as is the general scientific consensus, how can the most damaging consequences be averted? On page 457, Pierre Friedlingstein and colleagues use a modelling approach to explore some of the available mitigation options. Their results make salutary reading. Assuming median climate sensitivity, they find that reducing carbon dioxide emissions by $90 \%$ relative to the present-day level over the long term will not be sufficient to limit mean global temperature increase to $2{ }^{\circ} \mathrm{C}$ within the next millennium. Their analysis suggests that, even under this moderate scenario, radical action must be taken within the next two decades if the target is to be met. According to the numbers, this would require the achievement of zero emissions, as well as large-scale deployment of bioenergy combined with carbon capture and storage technologies, to actually reduce the amount of carbon dioxide already in the atmosphere. At higher climate sensitivities the task of climate mitigation becomes increasingly untenable.
Even assuming low climate sensitivity, their analysis suggests that delaying significant mitigation action for more than a decade could have serious consequences.

These are tall orders indeed. But despite the urgency of the matter in hand, many doubt that the COP17 negotiations will make significant progress towards any new legally binding international agreement to reduce greenhouse-gas emissions significantly, let alone achieve a genuine low-carbon economy anytime soon.

And yet, all is not gloom and doom. On page 426, Åsa Persson and Johan Rockström of the Stockholm Environment Institute describe how businesses are forging ahead with their own low-carbon standards, even as political negotiations flounder and prospects for any meaningful advance on Kyoto, Cancún and Copenhagen slip. Deniers - some of the more vociferous of them at least - see talk of dangerous climate change as part of some global anti-libertarian conspiracy against unfettered free-market capitalism and wealth creation, and an excuse for the imposition of personal and corporate tax rises. But it seems that many business and industrial leaders have already adopted a more nuanced, forward-looking position, not only reducing their carbon footprints through reductions in non-renewable-energy consumption, but seeing climate change as a positive opportunity for investment and research and development, rather than some kind of ball and chain. As Lord Stern put it at the pre-Cancún World Climate Summit, "the new industrial revolution has begun, and the business world is leading this challenge."

Could it be then that, as Persson and Rockström suggest may be the case, we have passed a political tipping point for momentum on carbon action, with businesses in the vanguard? Not necessarily. Many business leaders still perceive major economic and competitive risks in taking the initiative, and for now prefer a 'watch and see' approach instead. However, many companies are already reaping significant benefits from the more enlightened approach. Perhaps the tide is turning after all. Whether the politicians and policymakers attending the Durban negotiations are capable of providing the level of mutual cooperation and inspirational leadership required if we are to see a complete sea-change in attitudes and behaviours remains to be seen. 